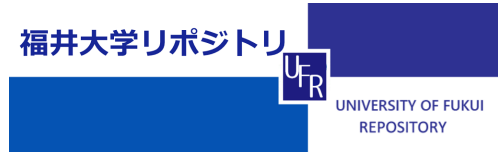

Det ecti on of Water Anount on the Surface of $\mathrm{G}$ ass Fi ber s Usi ng the Transi ent Leakage Current of Static El ectricity

\begin{tabular}{|l|l|}
\hline 著者 & $\begin{array}{l}\text { KAGAWA K i chi r o, SUG NO Yut aka, KAGAM } \\
\text { Kat suhi ko, UEDA Nasahi ro }\end{array}$ \\
\hline $\begin{array}{l}\text { j our nal or } \\
\text { publ i cat i on t i t l e }\end{array}$ & $\begin{array}{l}\text { I EEE Tr ansact i ons on I nst r ument at i on and } \\
\text { Measur ement }\end{array}$ \\
\hline vol une & I M 48 \\
\hline page $r$ ange & $66-68$ \\
\hline year & $1999-01$ \\
\hline URL & ht t p: //hdl . handl e. net /10098/1446 \\
\hline
\end{tabular}




\title{
Detection of Water Amount on the Surface of Glass Fibers Using the Transient Leakage Current of Static Electricity
}

\author{
Kiichiro Kagawa, Yutaka Sugino, Katsuhiko Kagami, and Masahiro Ueda
}

\begin{abstract}
A bundle of fibers (each $20 \mu \mathrm{m}$ in diameter) was sandwiched by electrodes, and a high voltage of $400 \mathrm{~V}$ was supplied to the electrodes to measure the leakage current flowing on the surface of the fiber. The leakage current is as low as the order of $\mathrm{mA}$. It was demonstrated that the current is almost linear relative to the water amount on the surface of the fibers in the examined range from 0.08 to $1.2 \%$ weight percent. This range is very important for the inspection of the fibers during the production stage in factories. A simple and practical instrument for detecting the amount of water is also presented.
\end{abstract}

Index Terms-Detection of water amount, glass fiber fabrication, leakage current of static electricity.

\section{INTRODUCTION}

$\mathbf{R}$ ECENTLY, various techniques based on opto-electronic engineering have been developed and applied to many production processes in factories for checking the product quality. However, an idea based on a simple and classical physical principle is sometimes still very useful even under conditions where modern techniques are not so effective or are quite powerless. Also, another advantage of a simple and classical method is its low cost. In a previous study [1], we proved that a pulse discharge technique, though it is a very old technique in science, is very useful to detect the leakage of pressure sensors.

In this study, the property of static electricity was shown to be successfully applied to detecting the water amount on the surface of glass fibers. Recently there have been many demands for glass fibers in industrial fields not only for use in optical fibers but also for materials with various functions. One of them is the application to a separator for a lead-sulfuric-acid battery. This kind of fiber has a homogeneous structure. The glass fiber was produced from melted glass by being pushed out of a nozzle. The molten glass was immediately cooled by exposure to a shower of cold water to form a thin fiber (20 $\mu \mathrm{m}$ in diameter), and it was rolled on a spindle. The fiber was cut to about $3 \mathrm{~m}$ in length and formed into a bundle. The bundle of glass fibers was then dried to reduce the water on the surface to a suitable level. The presence of adequate water on the surface of the glass fiber is very important when

Manuscript received September 8, 1998; revised January 11, 1999.

K. Kagawa, Y. Sugino, and M. Ueda are with the Faculty of Education, Fukui University. Fukui 910 , Japan.

K. Kagami is with Tarui Factory, Nihonmuki Co. Ltd., Gifu 503-21, Japan. Publisher Item Identifier S 0018-9456(99)02845-4.

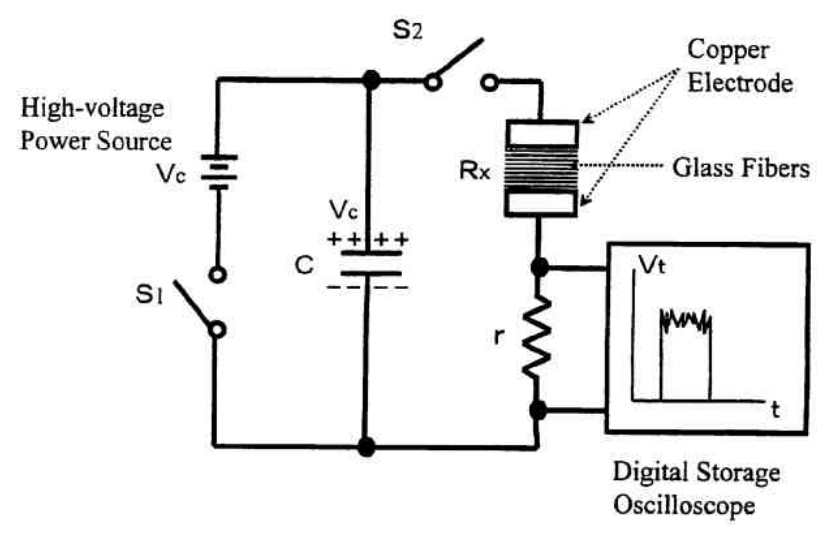

Fig. 1. Experimental setup used to measure the leakage current of static electricity flowing on the surface of glass fibers.

fabrication of the separator is done. The best condition for the water content is known to be in the range between 0.1 and 0.3 weight percent. The weight of water attached on the surface of the glass fiber can be calculated by subtracting the net weight of the glass fiber which is obtained after being completely dried. However, this method takes time, thus it was not often used on a practical basis. Usually in the production stage in factories, skilled persons check the water amount based on their intuition when they touch the fibers with their fingers. Therefore, development of a new method for detecting the water on the surface of glass fibers has been required in the industrial field. In the case of water in the atmosphere, we can employ an infrared absorption method. However, this method cannot be applied in this case because the glass itself has a high absorbance in the infrared spectral region. Also, the Raman spectroscopic technique is impractical in factories because of its high cost.

\section{PRinciple AND Experimental Method}

In a preliminary experiment, a leaf-electrometer was used to examine how the water on the surface of the fibers influenced the leakage of static electricity stored in the leaf-electrometer. As a result, it was proved that, depending on the humidity in the room in which the fiber bundle was placed and also on the time it was left in the room, leakage current characteristics were quite different when the fiber bundle was touched by the electrode of the leaf-electrometer. Namely, when the humidity was high, the leaf of the leaf-electrometer soon 


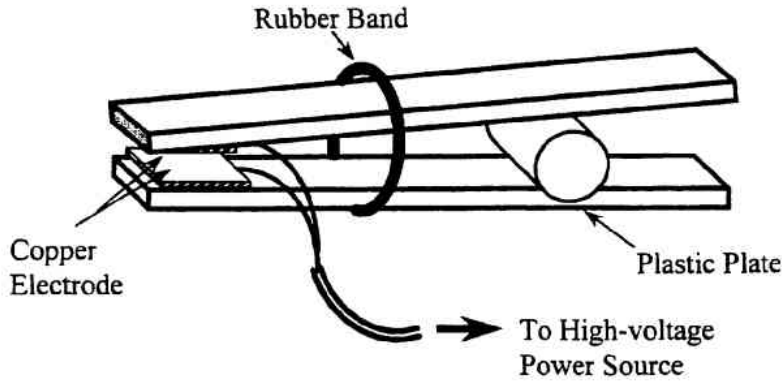

(a)

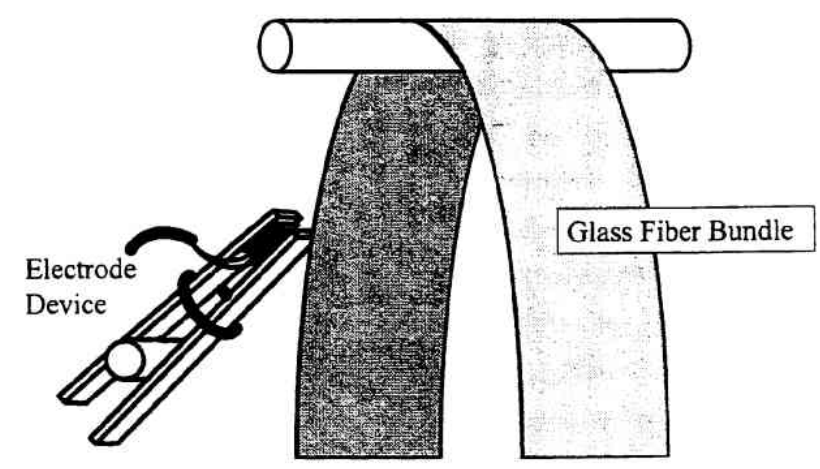

(b)

Fig. 2. (a) Illustration of the electrodes used for sandwiching the glass fibers and (b) illustration showing how the electrodes encompass the fiber bundle.

closed. However, when the fibers were completely dried in a dry box, the leaf of the leaf-electrometer did not close, showing essentially no electrical conductivity. Such a phenomenon is essentially the same as that well known as the leakage of the static electricity. It is believed that ions such as $\mathrm{Na}^{+}$are easily produced with the aid of water present on the surface of the materials and contribute to the electrical conduction [2]. Prior to this experiment, we tried to use a conventional megaohm meter which is normally used to check for electrical insulation. However, the meter proved to be useless when the water amount on the glass fiber to be measured was lower than about $0.5 \%$, showing infinite resistance.

In order to measure the transient leakage current, simple and compact equipment was designed and constructed. Fig. 1 shows the schematic diagram of the equipment. The bundle of fibers was sandwiched between two electrodes. A highvoltage power source used for a flash lamp in a commercial disposable camera was used in this experiment. First, capacitor $C$ (about $400 \mu \mathrm{F}$ ) was charged up to around $400 \mathrm{~V}$ by the highvoltage power source. The charge of static electricity flows through the surface of the fiber when switch $S_{2}$ was turned on immediately after the switch $S_{1}$ was disconnected. The leakage current can be calculated by the pick-up voltage detected with the resistance $r$; the resistance value was changed in the range from several tens of $k \Omega$ to several hundred $k \Omega$, depending on the water amount. The pick-up voltage was detected using a digital storage oscilloscope.

The current value varies with the thickness of the bundle of fibers and also with the pressure applied to the electrodes. The thickness of the bundle was kept constant at $10 \mathrm{~mm}$ in this experiment because this is the thickness during the production of the fibers. The illustration of the electrodes is shown in Fig. 2(a). Two copper-clad boards (size, $100 \times 150 \mathrm{~mm}$ ) were used for the electrodes. Each of the electrodes was stacked on a plastic plate $(100 \times 600 \times 10 \mathrm{~mm})$. In order to supply almost constant pressure when the electrodes sandwiched the fiber bundle, a rubber band was used.

Fig. 2(b) shows an illustration of how the electrodes sandwich the fiber bundle during the measurement. The gap between the two electrodes was expanded once, and the fiber bundle was sandwiched while hanging during the drying process. Subsequent to sandwiching the glass fibers, the electrical current started to flow and immediately attained a

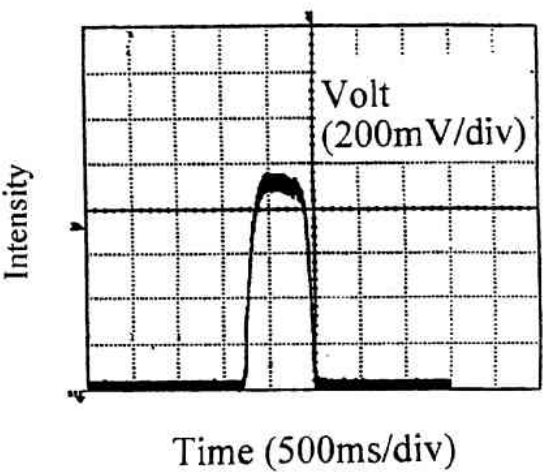

Fig. 3. Typical oscilloscope trace obtained from the experiment shown in Fig. 1.

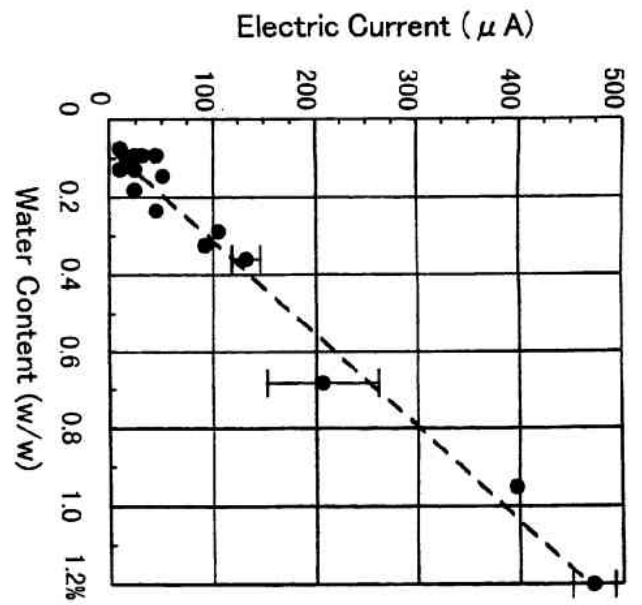

Fig. 4. Relationship between the water amount on the surface of glass fibers and the leakage current.

maximum value within a few hundred milliseconds. Therefore, the measurement was finished within a short time of about 0.5 s.

In order to obtain an accurate measurement of the water attached on the surface of the fibers, the weight of the bundle of fibers was measured twice, namely once just after the leakage current measurement, and again after being completely dried for $30 \mathrm{~min}$ in a desiccator box. The water amount was calculated from the difference in weight. 


\section{EXPERIMENTAL RESULTS}

Fig. 3 shows a typical oscilloscope trace obtained from the experiment shown in Fig. 1. The trace shows almost no decay. This is because the charge stored in capacitor $C$ is considerable, and the current flowing in the circuit is as low as $\mu \mathrm{A}$ in magnitude.

Fig. 4 shows the relationship between the water amount on the fiber surface and the leakage current. Many samples containing various amounts of water from 0.08 to $1.2 \%$ were used in this experiment. A linear relationship was observed.

As described above, the best condition for the water amount on the surface of the fiber is in the range between 0.1 and 0.3 weight percent. Therefore, on the basis of the results shown in Fig. 4, we can say that this method can be practically applied to the measurement of water on the surface of the fibers.

It was also observed that when the pressure applied to the electrodes increases, the slope of the straight line in Fig. 4 increases. This is probably due to increased pressure causing better contact among the fibers and as a result, the actual path length of the fibers between the electrodes became short.

\section{CONCLUSION}

It was proved that the charge stored in a high-voltage capacitor can flow through glass fibers which have water on their surface to some extent. The leakage current shows an almost linear relation to the water amount in the range between 0.08 and 1.2 weight percent. Therefore, based on the current value, we can derive the water amount. Although there are still many problems to be solved, this new method can be applied in factories as a highly sensitive, real-time method of determining a small amount of water attached on the surface of materials.

\section{REFERENCES}

[1] M. Ueda, K. Kagawa, Y. Sugino, K. Moriya, and T. Matsui, "A new method for detecting vacuum leakage of a pressure sensor using a pulse discharge technique," J. Phys. D: Appl. Phys., vol. 30, pp. 703-708, 1997.

[2] W. R. Harper, Contact and Frictional Electrification, 1967, pp. 76-96.

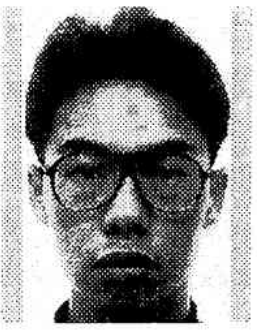

Yutaka Sugino was born in Matsuyama, Japan, in 1973. He received the B.Engr. degree in electronic engineering in 1996 and the M.Educ. degree in technology education in 1998, both from Fukui University, Fukui, Japan.

$\mathrm{He}$ is now with the Nippon Muki Co., Ltd., and the Research and Development Department, Tarui Factory, Nihonmuki Co. Ltd., Gifu, Japan.

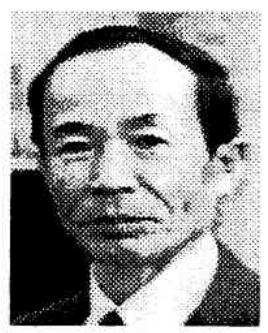

Katsuhiko Kagami was born in Gifu. Japan, in 1937. He received the B.Engr. degree in ceramic engineering in 1960 from Nagoya Institute of Technology, Nagoya, Japan.

From 1960 to 1985, he was engaged in the development of glass wool fibers, and from 1985 until his retirement in 1997, he was Head of the Department, Tarui Factory, Nihonmuki Co. Ltd. Gifu, Japan.

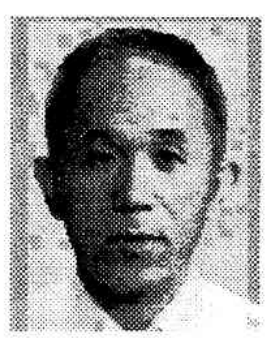

Masahiro Ueda was born in Fukui, Japan, on July, 12, 1943. He received the B.E., M.E., and D.E. degrees in electronic engineering from the University of Osaka Prefecture, Osaka, Japan, in 1966, 1968, and 1971, respectively.

From 1971 to 1975 , he was Assistant of Electronic Engineering, Ehime University. Japan, where he worked in the field of electron beam optics and optical holography. From 1975 to 1984 , he was Associate Professor, Technical Department, Faculty of Education, Fukui University, and since 1985, he has been Professor at the same department. His research interests are in electronics and optics for industrial measurement.

Dr. Ueda is a member of the Institute of Electronics, Information, and Communication Engineers of Japan, the Japan Society of Applied Physics, Medical Electronics and Biological Engineering of Japan, the Journal of the Japanese Society of Technology Education, and the Laser Society of Japan.

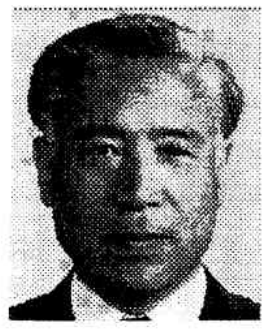

Kiichiro Kagawa was born in Hitachi, Japan, on December 15, 1994. He received the B.S., M.S.. and D.S. degrees from Konan University, Konan, Japan.

Since 1976, he has been an Associate Professor. Faculty of Education, Fukui University, Fukui, Japan. His research interests are laser plasma and its application.

Dr. Kagawa is a member of the American Society for Applied Spectroscopy, the Japan Society of Applied Physics, and the Spectroscopy Society of Japan. 